IV International Seminar on ORC Power Systems, ORC2017 13-15 September 2017, Milano, Italy

\title{
An experimental and numerical analysis of the performances of a Wankel steam expander
}

\author{
Marco Francesconi ${ }^{\mathrm{a}, *}$, Gianluca Caposciutti ${ }^{\mathrm{a}}$, Marco Antonelli ${ }^{\mathrm{a}}$ \\ ${ }^{a}$ Universitá di Pisa, D.E.S.T.eC., Largo Lucio Lazzarino, Pisa 56122, Italy
}

\begin{abstract}
In the last decades, the energy market increased its interest towards the smart grids and electrically isolated systems. These systems utilize small size power generator, which often feature volumetric expanders that are very robust and reliable for a wide range of operative conditions. In this work a study that focuses on a Wankel volumetric expander was carried out. In order to predict the extractable specific work from the expander, a thermodynamic lumped parameters numerical model was developed. The model was validated by means of experimental data obtained using water steam as working fluid. The experimental results encouraged the need to improve the research of this expander, as well as the capability of the numerical model to predict the effective performances of the device.
\end{abstract}

(C) 2017 The Authors. Published by Elsevier Ltd.

Peer-review under responsibility of the scientific committee of the IV International Seminar on ORC Power Systems.

Keywords:

Wankel Expander, Experimental tests, Numerical modelling, ORC technology.

\section{Introduction}

The increment of energy consumptions, the need to reduce pollutant emissions and the limited reserves of fossil fuels increase the necessity of energy production from renewable sources. In order to produce useful power, solar energy, biomass, geothermal heat and waste heat recovery are technologies that may provide low grade heat. In this context, the Organic Rankine Cycle is a suitable technology that allows the exploitation of these sources [1-3]. Considering low size plants, a key components of an ORC cycle is the expander whose performances and costs results in an higher plant efficiency, than using turbines [1,4-6].

As reported in [7,8], several devices, such as scroll and vane expanders, are suitable for low output powers (up to $10 \mathrm{~kW}$ ), while reciprocating expanders are employed for power range between 25 and $100 \mathrm{~kW}$. On the other hand, turbines are attractive to produce power higher than $1 \mathrm{MW}$ [4]. Nevertheless, volumetric expanders are suitable for the systems in which a low vapor quality is obtained at the end of expansion process.

\footnotetext{
* Corresponding author. Tel.: +39-050-2217133; fax: +39-050-2217160

E-mail address: marco.francesconi@ for.unipi.it
} 
The literature reports several studies about different volumetric devices [8], even if only few prototypes are commercially available in the range 10-50 kW. In particular several studies investigated the performances of volumetric expanders for waste heat recovery focusing the analysis on piston, scroll and screw machines [9-11]. The design of a volumetric expander, obtained by a Wankel engine, was developed at Pisa University to match this power range. The technical feasibility of this project, was demonstrated considering previous studies [12-15]. Particularly, a Wankel expander may be suitable for technical applications because of a series of advantages in terms of compactness, economy and reduced mechanical vibrations [6]. Moreover, the main troubles due to wear of seals as well as poor fuel economy and emissions are avoided because of the lowest values of the operating pressure and temperature together with the absence of the combustion process.

Previous studies about the Wankel device investigated the effects due to the timing variation [16] and the influence of the discharge coefficient of the valves [17], while in [18] a comparison of the first experimental results, employing compressed air and saturated steam, was shown.

In this study, several experimental tests based on the use of saturated water steam as working fluid, were performed on the Wankel prototype. The main purpose was to investigate the global performances of the expander in terms of rotating speed, indicate cycle and mechanical power. The experimental data were then compared with numerical results predicted by a numerical model of the device and a good agreement was found. Particularly, the differences between the indicated cycle work simulated and measured were less than $15 \%$. Finally, it was proved that the developed code may be suitable to predict the real performances of the Wankel expander fueled with organic fluid for ORC micro-generation applications.

\section{Features of the Wankel prototype}

The Wankel device was developed at the University of Pisa employing the bearings, the main shaft and the seals of an original Wankel engine used in karts and ultra-light flight vehicles. In order to increase the compression ratio, the original rotor was replaced by another one without cavities, while the stator was newly built to accommodate rotating valves. A pulleys system, connecting the engine to the shaft, drove the valves (Figure 2) whose timing was enabled by a vernier system. The first admittance valve is situated $17^{\circ}$ after the Top Death Center (i.e. TDC) and the first exhaust valve is situated after $115^{\circ}$ from the TDC; the other couple is symmetrically displaced. The geometry and the kinematic of the device ( see Figure 1(a) ) allowed to perform two thermodynamic cycles for each operating chamber during a full rotation of the rotor, requiring two intake and two exhaust valves overall. In particular, the stator shape of a Wankel device is determined by the ratio of of the value of the eccentricity $e$ to the rotor radius $R$ shown in in Figure 1(a).

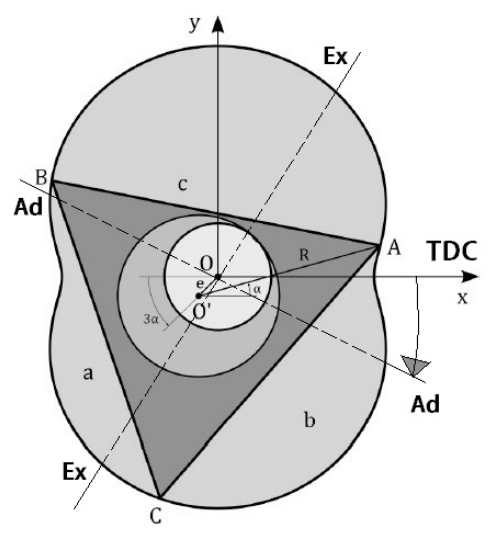

(a) Wankel expander geometry. Ad and Ex are the admittance and exhaust valves position respectively



(b) A single thermodynamic $\mathrm{p}-\mathrm{V}$ cycle

Fig. 1: General schemes of the Wankel expander system 
Considering the general concepts of the theory of volumetric expander and the ideal thermodynamic cycle in Figure 1(b), the following parameters can be calculated according to the literature [16]:

$$
\begin{aligned}
& \text { Volume ratio }=\frac{V_{\text {disp }}+V_{0}}{V_{0}} \\
& \text { Admission grade }=\frac{V_{2}-V_{1}}{V_{d i s p}} \\
& \text { Recompression grade }=\frac{V_{5}-V_{6}}{V_{d i s p}}
\end{aligned}
$$

In the following Table 1 and Figure 2, the main design parameters of the prototype are summarized. In particular, it was also possible to describe the variation of the displacement of the rotary piston by means of an equivalent value of the crankshaft of a reciprocating engine.

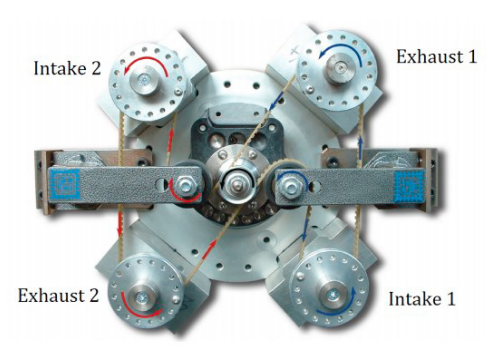

Fig. 2: Wankel expander pulley system

\begin{tabular}{lc} 
Parameter & Value \\
\hline Number of rotors & 1 \\
Displacement & $3.1610^{-4} \mathrm{~m}^{3}$ \\
Eccentricity & $1.20510^{-2} \mathrm{~m}$ \\
Equivalent crank & $1.90510^{-2} \mathrm{~m}$ \\
Volume ratio & 12.7 \\
Admission grade & 0.4 \\
Recompression grade & 0.3 \\
\hline
\end{tabular}

Table 1: Design parameters of the prototype

\section{Numerical model}

A lumped parameter model of the Wankel expander was developed in Matlab ${ }^{\circledR}$ in stationary conditions and the use of the Refrop ${ }^{\circledR}$ database allowed to simulate several working fluids. The output data were the indicated cycle and the global evaluation of different losses such as apex sealing friction, bearing consumption, leakages and the heat fluxes at the coating.

The different aspects of the modelling were faced considering a bibliographic research reported in [19], that provided suggestions about friction losses and thermal exchanges in rotary devices.

In particular, the several mass flow rates due to the valves or leakages were treated as a flow through a nozzle $[6,19]$ employing a proper value of the discharge coefficient [16,17]. This modelling was possible considering small angular increments, characterized by restrained pressure drops, that allowed the introduction of a medium heat capacity ratio of the fluid. Another consequence of this assumption was the reduction of the computational effort.

The code evaluated the kinematic analysis considering the geometrical data as input. After, the introduction of the operating conditions allowed to calculate the values of pressure for each angular position; outputs were then employed as inputs for the dynamic analysis of the seals. In particular, this investigation allowed to introduce a leakage flow when an absence of contact between the stator case and seal was found. Consequently, it was necessary to solve simultaneously the fluid dynamic and the dynamical systems because, as well known, the leakages influence the operating pressure of the chambers. The algorithm was repeated for each angular position of the rotor, until the difference between the values of pressure evaluated at 180 and 0 degrees was less than 0.001 . Finally, the values of the pressure were treated as loads for the mechanical analysis of the several parts of the device by means of the use of Newtons laws. During this step the losses due to bearings were calculated by means of proper relations [19] and the main result was the value of the mechanical torque of the main shaft and then of the mechanical power. 


\section{Experimental tests}

In the tests, the expander was fueled employing water saturated steam. The operating fluid was produced by means of a Kettle heat exchanger in which the water was heated by an auxiliary diatermic oil circuit. The process heat was provided by a boiler fueled with biomass. After the expansion, a shell and tube condenser cooled the steam and the condensate was finally pumped into the Kettle boiler by means of a pump (Figure 3 ).

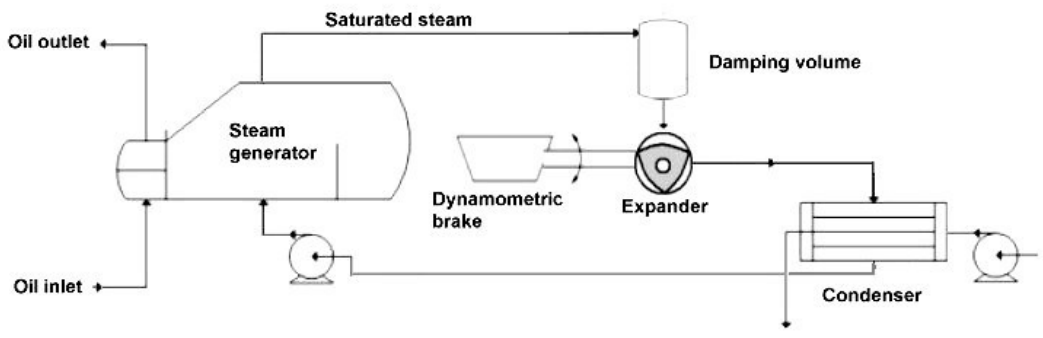

Fig. 3: Scheme of the plant for the experimental tests

The mechanical power was measures installing the expander on a dynamic test bench. Generally, in a rotary engine each operating chamber is moving with the rotor motion; consequently, the whole thermodynamic cycle can be captured employing a proper number of sensors placed at an adequate angular position. As conclusion, only two sensor probes $P_{1}$ and $P_{2}$ were sufficient to acquire all the indicated cycle in the Wankel expander. For this purpose, the piezo-electric sensors Kistler $6052 \mathrm{C}$ were employed (sensitivity $\approx 20 \mathrm{pC} / \mathrm{bar}$ and linearity $< \pm 0.3 \% / \mathrm{FSO}$ ). Each sensor was placed in the stator case by means of a M4x0.35 housing and the hole depth allowed the direct access to the expansion chamber. In Figure 4 the pressure probe position and the valve ducts displacement are shown together with the pressure acquisition sequence.

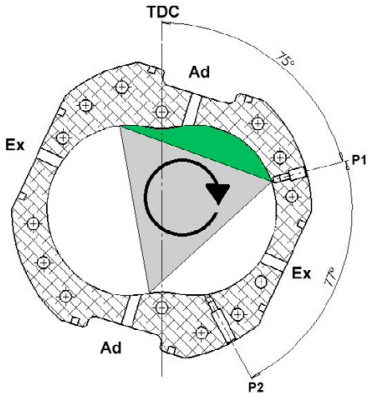

(a) First sensor acquisition

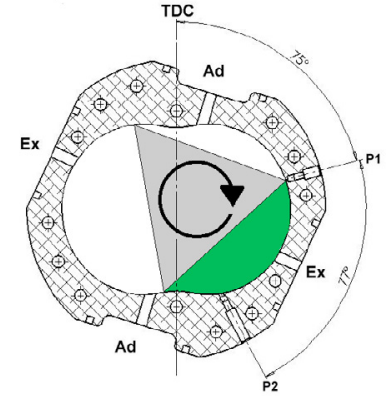

(b) Sensors measure overlapping

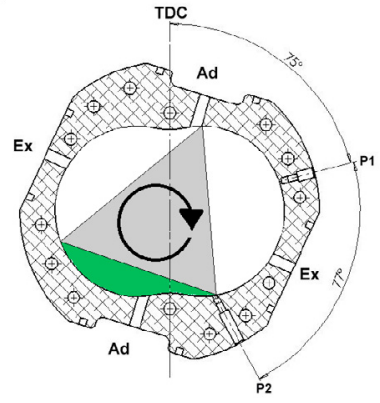

(c) Acquisition ends

Fig. 4: Example scheme of the pressure probes data acquisition. The green area is the internal chamber monitored by $\mathrm{P}_{1}$ and $\mathrm{P}_{2}$; while the $\mathrm{x}$-axis passes through the TDC position. Ad and Ex are the admittance and exhaust ducts, respectively.

The pressure signals were then conditioned by means of a Kistler 5064A1 charge amplifier. The angular position of the main shaft was measured by means of an encoder Elcis 38Q. All the signals were gathered by a National Instrument Compact DAQ system in which a NI9174 chassis was used together with the NI9223 board for the pressure acquisition and the NI9411 for the digital signal encoder acquisition. The encoder actuated the data capture by means of the trigger/clock signals. Particularly, the trigger signal was sent at TDC, while the clock signal was acquired for each shaft degree variation. The pressure oscillations, due to the pulsating behaviour of the device, were reduced by means of a damping volume of $50 \mathrm{~L}$ placed upstream to the expander. The inlet and discharge pressure were also acquired to characterize the operating conditions. 
Finally, a LabView program managed the recombination of the signals of the two pressure probes $\mathrm{P}_{1}$ and $\mathrm{P}_{2}$ together with those of the encoder, to obtain the pressure curve as a function of the angular position of the main shaft.

The tests were performed choosing an inlet pressure equal to 5, 6 and 7 barA. The condensing pressure was kept at 0.75 barA by means of a temperature PID controller, which regulated the cooling water flow rate. Moreover, three different values of rotating speed $(1000,2000$ and $3000 \mathrm{rpm})$ were employed as operating conditions for each inlet pressure used. In order to estimate an experimental error for the acquired data, 100 cycles/test were acquired for every test condition. For each test, a post-processing in Matlab ${ }^{\circledR}$ program revealed that the average percentage difference between the pressure data in the same cycle position was below the $15 \%$, while its mean value was below $6 \%$.

\section{Results and Discussion}

In this Section, the main results are shown. In order to compare experimental results, the simulated data were generated employing the same boundary conditions of the experimental tests (i.e. same rotational speed and admitting pressure). The output data were managed by interpolated maps to show the main trend of the involved quantity. The measured and simulated indicated pressures were then compared (Figure 5).

The effect due to the increase of the rotating speed consisted in a shape deformation of the measured and predicted indicated cycles. As well known, higher values of rotating speed create greater pressure losses through valves. Particularly, the main effect was the slowdown of the pressure drop with the increase of rotating speed during the exhaust phase. Clearly, a difference of values between the measured and simulated exhaust pressure might appear. This fact was explained considering also the numerical value of the discharge coefficient whose value in the code was measured at fluid dynamic test bench in stationary conditions [17], while in the operating conditions the presence of unsteady flow might play a non negligible role. The effect was greater for the exhaust valve because of the low density of the fluid.

The model captured also the influence due to the intake and exhaust ducts geometry [17], in which leakages and disturbs of the pressure at the end of the discharge stroke occurred. Clearly, this last effect was less relevant with the increase of the rotating speed. Another effect, that was described by the model, was the opening of the inlet valve that appeared as a little curl. This effect appeared since the valve opening had no advance, and during the opening time the pressure losses across the valves caused a decrease of the chamber pressure. Finally, the differences between the measured and predicted indicated cycles were calculated by means of the estimator E defined in the following Equation 4:

$$
E=1-\frac{L_{\text {sim }}}{L_{\text {exp }}}
$$

in which the terms $L_{s i m}$ and $L_{\text {exp }}$ are the simulated and experimentally acquired cycle work, respectively. For the analyzed cases, the value of the estimator ranged between -6.5 and $7 \%$ (Figure 6).

As for the mechanical losses (Figure 7), due to ancillary friction, bearings friction and sealing friction, the simulations showed that they grew with the rotational speed, while they were barely influenced by the admitting pressure. This behaviour was explained considering the inertia loads that, being proportional to the square of the rotating speed, increased the stresses of the bearings and of the apex seals with a corresponding amount of the friction losses. On the other hand, higher values of the inlet pressure involved an higher temperatures causing an increase of thermal losses. These results agreed with the theory on the rotary engines, thus confirming, at least from a qualitative analysis, the validity of the numerical model.

From a global point of view, the difference between measured and simulated power and torque (see Table 2 and Figure 8 ) was contained within 15\%. Finally, the predicted isentropic efficiency showed values between 0.4-0.7, while the volumetric efficiency, defined as the ratio of the ideal flow rate to the real value, was between 0.85-0.9.

\section{Conclusion}

In this study the comparison between the experimental and simulated data of a Wankel expander fueled with saturated steam is presented. The experiments were carried out considering three levels of the inlet pressure and three 
different values of the rotating speed. The condensing pressure was maintained constant for each test. The numerical model appears as a reliable tool to predict the real power and the real indicated cycle of the device. As demonstrated in the most of the tested cases, the average value of the difference between the measured and simulated data was below the $10 \%$, while its maximum value was up to $15 \%$. This work represented the capability, numerically and experimentally proved, of the Wankel device as volumetric expander also with saturated steam as working fluid.

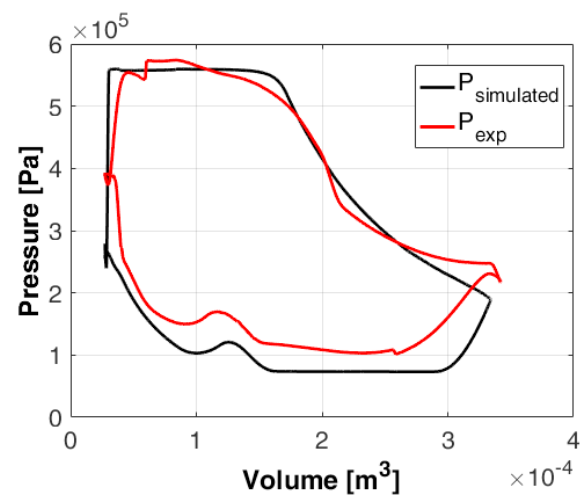

(a) $1000 \mathrm{rpm}-5$ barA

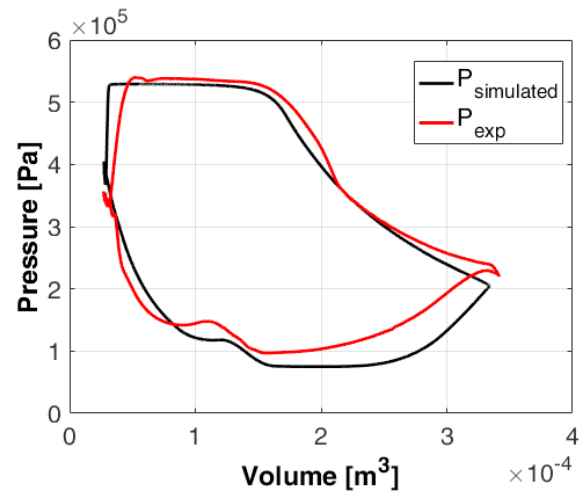

(c) 2000 rpm - 5 barA

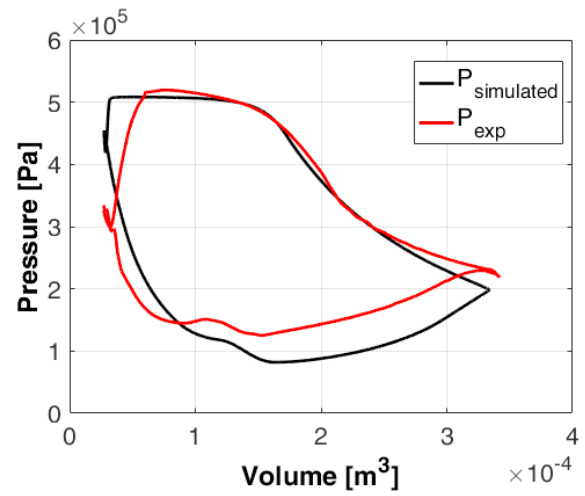

(e) $3000 \mathrm{rpm}-5$ barA

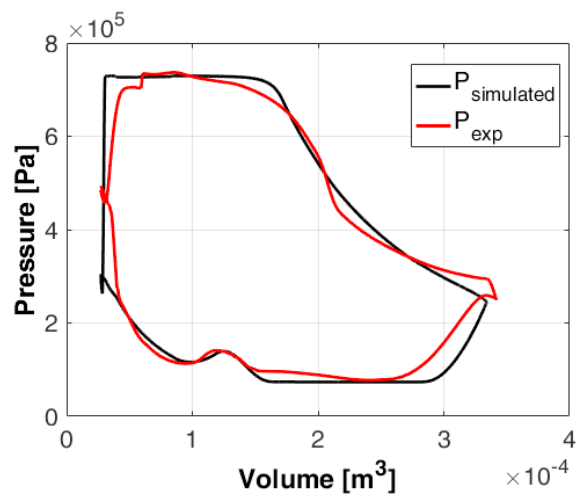

(b) 1000 rpm - 7 barA

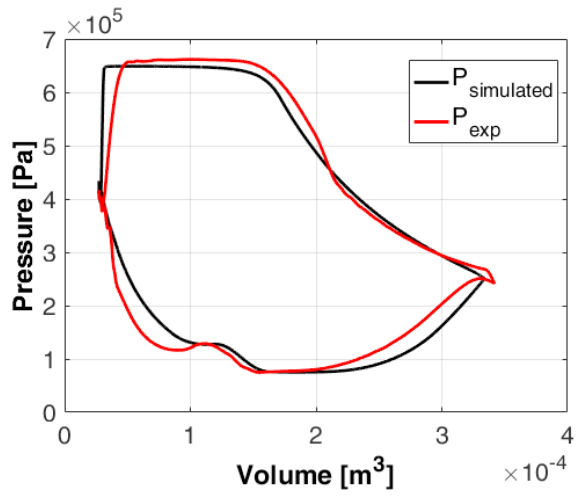

(d) $2000 \mathrm{rpm}-7$ barA

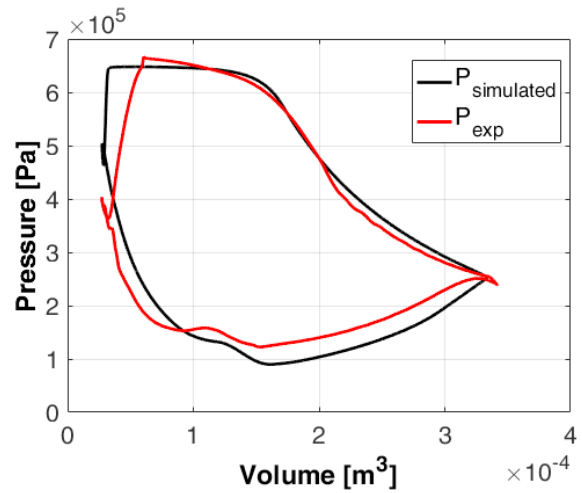

(f) $3000 \mathrm{rpm}-7$ barA

Fig. 5: Predicted and measured indicated cycle for different rotating speed and admitting pressure

\section{References}

[1] S. Quoilin, M. Van Der Broek, S. Declaye, P. Dewallef, V. Lemort, Techno-economic survey of Organic Rankine Cycle (ORC) systems. Renewable and Sustainable Energy Reviews 22 (2013) 168-186. 


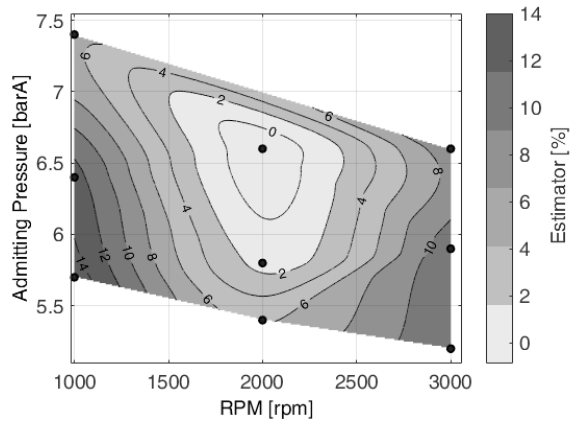

Fig. 6: Estimator value map

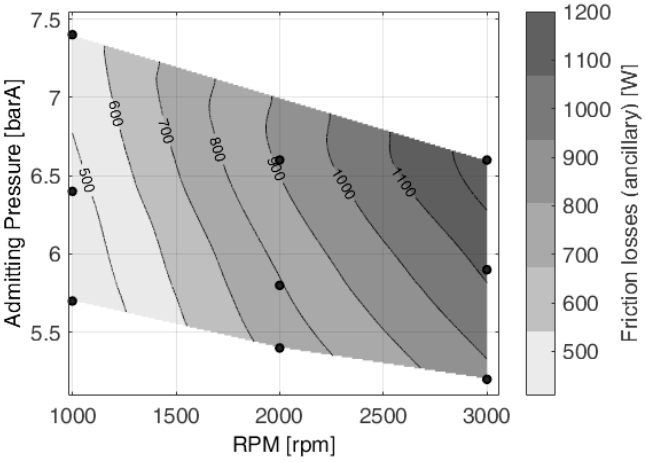

(a) Friction loss from ancillary systems

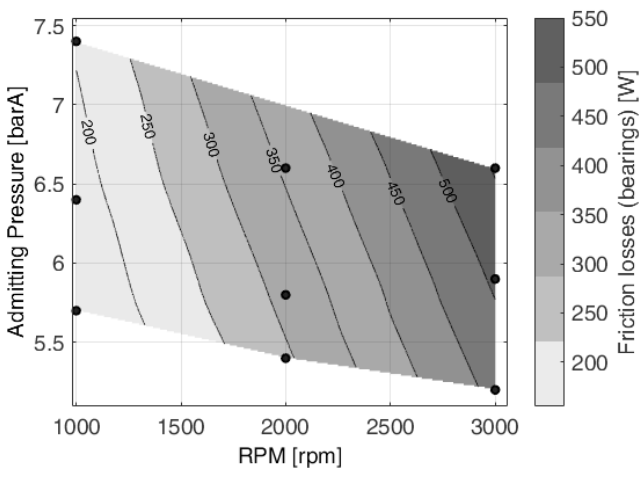

(c) Friction loss from bearings systems

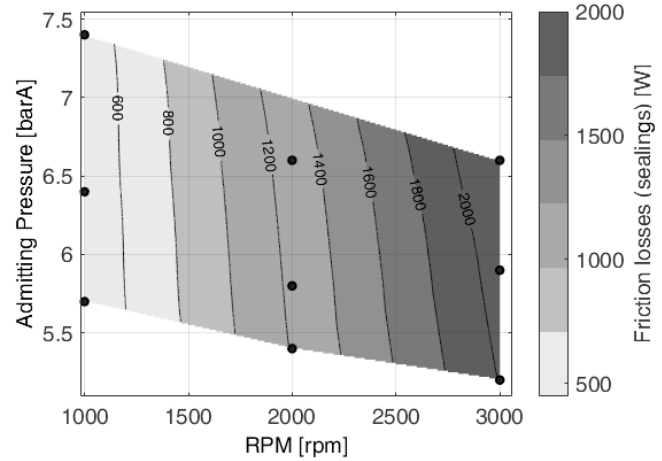

(b) Friction loss from the sealing system

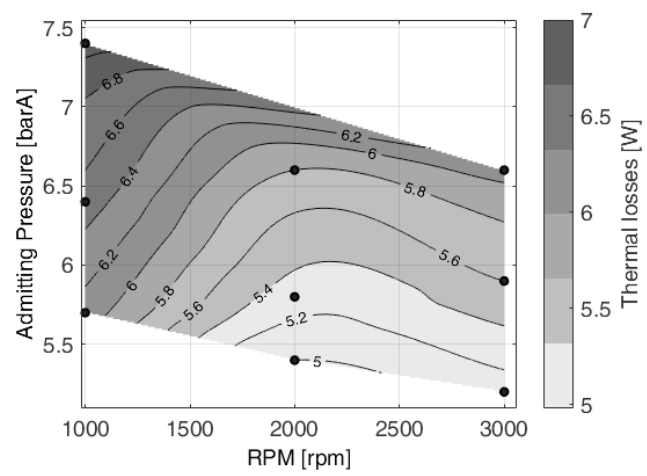

(d) Thermal losses

Fig. 7: An overview of the Wankel simulated losses

[2] J. Twidell, T. Weir, Renewable Energy Resources, second edition, Taylor and Francis group.

[3] H. Chen, D. Yogi Goswami, E. K. Stefanakos, A review of thermodynamic cycles and working fluids for the conversion of low-grade heat. Renewable and Sustainable Energy Reviews 22 (2013) 168-186.

[4] S. Quoilin, S. Declaye, A. Legros, L. Guillaume,V. Lemort, Working fluid selection and operating maps for Organic Rankine Cycle expansion machines. International Compressor Engineering Conference at Purdue, July 16-19,2012.

[5] V. Lemort, A. Legros, Positive displacement expanders for Organic Rankine Cycle systems (ORC) Power Systems (2017) 361-396.

[6] M. Antonelli, A. Baccioli, M. Francesconi, U. Desideri, L. Martorano ,Operating maps of a rotary engine used as an expander for microgeneration with various working fluids. Applied Energy 113 (2014) 742-750.

[7] A. P. Weiß,Volumetric expander versus turbine-which is the better choice form small ORC plants?. $3^{\text {rd }}$ International Seminar on ORC Power Systems, October 12-14, 2015, Brussels, Belgium.

[8] M. Imran, M. Usmana, B. S. Parka, D. H. Leea, Volumetric expanders for low grade heat and waste heat recovery applications. Renewable and 


\begin{tabular}{cccccc} 
Rotational speed & Admitting Pressure & Power $_{\text {sim }}$ & Torque $_{\text {sim }}$ & Power $_{\text {exp }}$ & Torque $_{\text {exp }}$ \\
\hline$[\mathrm{rpm}]$ & {$[\mathrm{barA}]$} & {$[\mathrm{kW}]$} & {$[\mathrm{N} \mathrm{m}]$} & {$[\mathrm{kW}]$} & {$[\mathrm{N} \mathrm{m}]$} \\
\hline \multirow{2}{*}{1000} & 5.7 & 3.0 & 29 & 2.7 & 26 \\
& 6.4 & 3.5 & 33 & 3.8 & 36 \\
& 7.4 & 4.1 & 39 & 4.8 & 46 \\
\hline \multirow{2}{*}{2000} & 5.4 & 5.2 & 25 & 5.4 & 26 \\
& 5.8 & 5.7 & 27 & 6.7 & 32 \\
& 6.6 & 6.8 & 33 & 8.4 & 40 \\
\hline \multirow{3}{*}{3000} & 5.2 & 6.7 & 21 & 7.2 & 23 \\
& 5.9 & 7.9 & 25 & 9.2 & 29 \\
& 6.6 & 9.1 & 29 & 10.0 & 32 \\
\hline
\end{tabular}

Table 2: Data from experimental (exp) and simulated (sim) tests

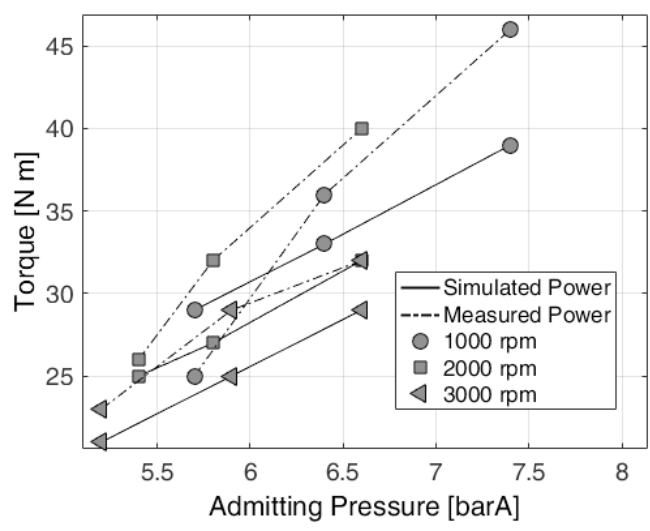

(a) Measured and simulated total Torque

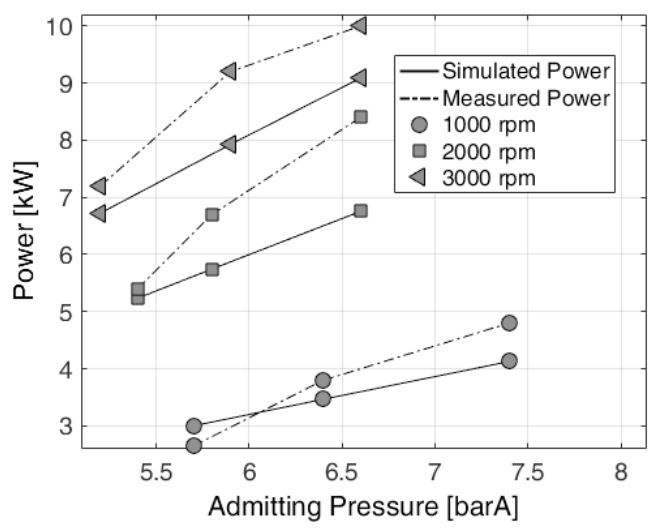

(b) Measured and simulated total Power

Fig. 8: Values of simulated and experimental power and torque

Sustainable Energy Reviews 57 (2016) 1090-1109.

[9] L. Guillaume, A. Legros, S. Quoilin, S. Declaye, V. Lemort, Sizing models and performance analysis of volumetric expansion machines for waste heat recovery through organic Rankine cycles on passenger cars. 8th International Conference on Compressors and their Systems 2013, 431-443.

[10] P. Garga, G.M. Karthika, P. Kumarb, P. Kumar, Development of a generic tool to design scroll expanders for ORC applications. Applied Thermal Engineering 109 Part B 2016, 878-888.

[11] B.S. Preethama, L. Weiss, Investigations of a new free piston expander engine cycle, Energy 106, 2016, 535-545.

[12] O. Badr, S. Naik, P.W. O’Callaghan, S.D. Probert Rotary Wankel engines as expansion devices in steam Rankine-cycle engines. Applied Energy 39(1) (1991) 59-76.

[13] O. Badr, S. Naik, P.W. O’Callaghan, S.D. Probert, Wankel engines as steam expanders: design considerations. Applied Energy 40(2) (1991) 157-170.

[14] M. Antonelli, L. Martorano, R. Lensi, Development and validation of a numerical model of a rotary steam engine for electric power micro generation using biomass. Proceeding of the ECOS Padova Congress (2007).

[15] M. Antonelli, L. Martorano , A study on the rotary steam engine for distributed generation in small size power plants. Applied Energy 97 (2012) 642-647.

[16] M. Antonelli, A. Baccioli, M. Francesconi, L. Martorano, Experimental and numerical analysis of the valve timing effects on the performances of a small volumetric rotary expansion device. Energy Procedia 45 (2014) 1077-1086.

[17] M. Antonelli, A. Baccioli, M. Francesconi, L. Martorano, Numerical and experimental analysis of the intake and exhaust valves of a rotary expansion device for micro generation. Energy Procedia 81 (2015) 461-471.

[18] M. Antonelli, M. Francesconi, A. Baccioli, G. Caposciutti, Experimental results of a Wankel-type expander fuelled by compressed air and saturated steam. ICAE 2016 8-11 October China.

[19] M. Francesconi, Analysis and design of devices for medium temperature solar thermal energy conversion etd-01092017-161721 ISBN 97888-902289-4-0. 